\title{
A Pintura de João Sebastião da Costa: a iconografia no espaço sagrado e profano ${ }^{1}$
}

\author{
La pintura de João Sebastião da Costa: iconografía en el espacio sagrado \\ y profano
}

\author{
João Sebastião da Costa's Painting: the iconography in the sacred and \\ profane space
}

\author{
Ms. Valéria Pereira Moreira \\ Dr. José Serafim Bertoloto ${ }^{3}$ \\ Dr. Juliano Batista dos Santos ${ }^{4}$ \\ Dra. Ana Graciela Mendes Fernandes da Fonseca Voltolini ${ }^{5}$
}

\begin{abstract}
Resumo
João Sebastião da Costa é um artista mato-grossense com uma criatividade ímpar, construiu seu legado e marcou a sua existência no cenário brasileiro, das artes visuais. Suas onças antropomórficas romperam os parâmetros das artes, ao se destacar nos inúmeros Salões de Arte Brasileira. A onça não era apenas o animal, ela precisava ter algo mais que isso, então ele elaborou aquilo, que o marcou, que o consagrou: a figura antropomórfica, mítica, encantada, provocativa, curiosa, que observa na espreita, um ser descrito pela crítica de arte, Aline Figueiredo "homem-bicho-santo", cujos cenários transcendem os limites do real, os seres encantados, a celebração da natureza, a ambiência composta pela fauna, flora, a religiosidade, a devoção, a magia, na imensidão da espacialidade do cerrado, fez um artista peculiar. Na pintura em estudo o artista nos apresenta a figura do São Sebastião, repousando no interior da barriga da serpente, que nos remete à lenda do Minhocão do Parí, que habita o universo mítico dos ribeirinhos do Rio Cuiabá. O santo posicionado na parte inferior do quadro, devorado pela serpente, cria uma atmosfera singular, nos remetendo ao processo colonial na América Latina, uma vez que, o artista cria um cenário mítico, jocoso, cercado de religiosidade, onde seu lugar de fala sobrepõe aos ditames judaico-cristãos. Os fluxos de informações, que transitaram na América Latina, numa circulação e encontro de objetos e pessoas com suas práticas culturais distintas, que se cruzam e produzem outras práticas culturais inusitadas, como vemos na pintura de João Sebastião da Costa, a representação decolonial dos seus santos.
\end{abstract}

Palavras-Chave: João Sebastião da Costa; artista mato-grossense; iconografia; sagrado e profano; decolonial; América Latina.

\footnotetext{
${ }^{1}$ Artigo apresentado durante o I Congresso Internacional Online de Estudos sobre Culturas - \#Culturas, realizado de forma online, em outubro de 2019.

${ }^{2}$ Mestre em Comunicação e Semiótica pela Pontifícia Universidade Católica de São Paulo - (PUC-SP); doutoranda do Programa de Pós-Graduação em Estudos de Cultura Contemporânea na Universidade Federal de Mato Grosso (ECCO-UFMT); Cuiabá, Mato Grosso; Brasil; amoravaleria@gmail.com

${ }^{3}$ Doutor em Comunicação e Semiótica pela Pontifícia Universidade Católica de São Paulo - (PUC-SP); Professor do Programa de Pós-Graduação em Ensino da Universidade de Cuiabá - (UNIC) e Colaborador do Programa de Pós-Graduação em Estudos de Cultura Contemporânea na Universidade Federal de Mato Grosso (ECCO- UFMT); Cuiabá, Mato Grosso, Brasil; serafim.bertoloto@ gmail.com

${ }^{4}$ Doutor e Mestre em Estudos de Cultura Contemporânea pela Universidade Federal de Mato Grosso - (ECCOUFMT); Docente de Filosofia do Instituto Federal de Mato Grosso - (IFMT); Cuiabá, Mato Grosso, Brasil; julianojbs@gmail.com

${ }^{5}$ Doutora em Comunicação Social - UMESP; Professora do Programa de Pós-Graduação em Ensino da Universidade de Cuiabá - (UNIC); fonsecaanagraciela@gmail.com
} 


\begin{abstract}
Resumen
El artista João Sebastião da Costa es un artista Mato-Grossense con una creatividad única, construyó su legado y marcó su existencia en la escena brasileña de las artes visuales. Sus jaguares antropomorfos rompieron los parámetros de las artes, cuando destacó en los numerosos Salones de Arte Brasileño. El jaguar no solo era el animal, ella necesitaba tener algo más que eso, así que elaboró lo que lo marcó y lo consagró: la figura antropomórfica, mítica, encantada, provocativa, curiosa, acechando, un ser descrito por la crítica de arte, Aline Figueiredo "hombre-bestia-santo", cuyos escenarios trascienden los límites de lo real, los seres encantados, la celebración de la naturaleza, el entorno compuesto de fauna, flora, religiosidad, devoción, magia, inmensidad. Del espacio del cerrado, lo convirtió en un artista peculiar. En la pintura en estudio, el artista nos presenta la figura de San Sebastián, que descansa dentro del vientre de la serpiente, que nos remite a la leyenda del Minhocão do Parí, que habita el universo mítico de la ribera de Cuiabá. El santo ubicado en el fondo de la pintura, devorado por la serpiente, crea un ambiente único, refiriéndose al proceso colonial en América Latina, ya que el artista crea una escena mítica y jocular rodeada de religiosidad, donde su lugar de expresión supera a la los dictados judíos. El flujo de información que ha transpirado en América Latina, en un movimiento y encuentro de objetos y personas con sus prácticas culturales distintas, que se intersecan y producen otras prácticas culturales inusuales, como vemos en la pintura de João Sebastião da Costa, la representación descolonial de sus santos.
\end{abstract}

Palabras clave: João Sebastião da Costa; el artista mato-grossense; iconografia; sagrado y profano; decolonial; América Latina.

\begin{abstract}
João Sebastião da Costa is a Mato Grosso with a unmatched criavitvit, built has legacy and marcked its existence in the Brazilian scenery of the visual arts. Your anthropomorphic ounces broken the parameters of the arts, by standyn out in the numerous Brazilian Art Halls. The jaguar wasn't just the animal, she needed to have something more than that. So he elaborated that marked him that consecrated him: the anthropomorphic figure, mythical, enchanted, provocative curious, who watches on the prowl a being described by art critic, Aline Figueiredo "man-animal-saint", whose scenarios transcend the bondaries of the real the enchanted beings, the celebration of nature the ambience composed by the fauna, flora the religiosity devotion, magic, in the vastness of the cerrado's spatiality made a peculiar artist. In the painting under study the artist presents the figure of São Sebastião, resting inside the snake's belly, wich refers to the Minhocão do Parí, that inhabits the mythical universe of the riverside of the Cuiabá River. The saint positioned at the bottom of the frame, devoured by the snake, creates a unique atmosphere, reffering us to the colonial process in Latin America, since the artist creates a mythical playful scenario, surrounded by religiosity, where his place of speech overlaps with Judeo-Christian dictates. Information flows that transited in Latin America in a circulation, and meeting objects and people with their distinct cultural practices that intersect and produce other unusual cultural practices, as we see in João Sebastião da Costa's painting, the decolonial representation of his saints.
\end{abstract}

Keywords: João Sebastião da Costa; Mato Grosso Artist; iconography; sacred and profane; decolonial; America Latina.

\title{
1. Introdução
}

João Sebastião Francisco Costa nasceu em Cuiabá-MT no dia 23 de junho de 1949, faleceu num domingo, 28 de fevereiro de 2016, deixou a cidade órfã de uma criatividade ímpar, construiu seu legado e marcou sua existência no cenário brasileiro, das artes visuais. Filho de mãe ceramista, Dona Alexandra, aprendeu desde pequeno, o ofício da argila, ajudando a mãe a pintar as peças do presépio, a convivência com o universo das cores, das 
tintas, despertou no futuro artista, a habilidade que o fez único. Suas onças antropomórficas romperam os parâmetros das artes, ao se destacar nos inúmeros Salões de Arte Brasileira, realizados por prefeituras (de São Caetano/SP), museus e outras instituições conceituadas nos anos 1970 a 1980, quando o país estava mergulhado na ditadura civil militar.

Aos 16 anos, em 1966 João Sebastião iniciaria os estudos do ensino médio, necessitando sair de Cuiabá em busca de mais conhecimentos nas artes, se mudou para Niterói - RJ para a casa de familiares maternos. No percurso da viagem, fez uma pausa na cidade de Campo Grande, tempos do Estado Único, quando conheceu a jovem Aline Figueiredo, hoje exímia crítica de arte e o consagrado artista Humberto Espíndola.

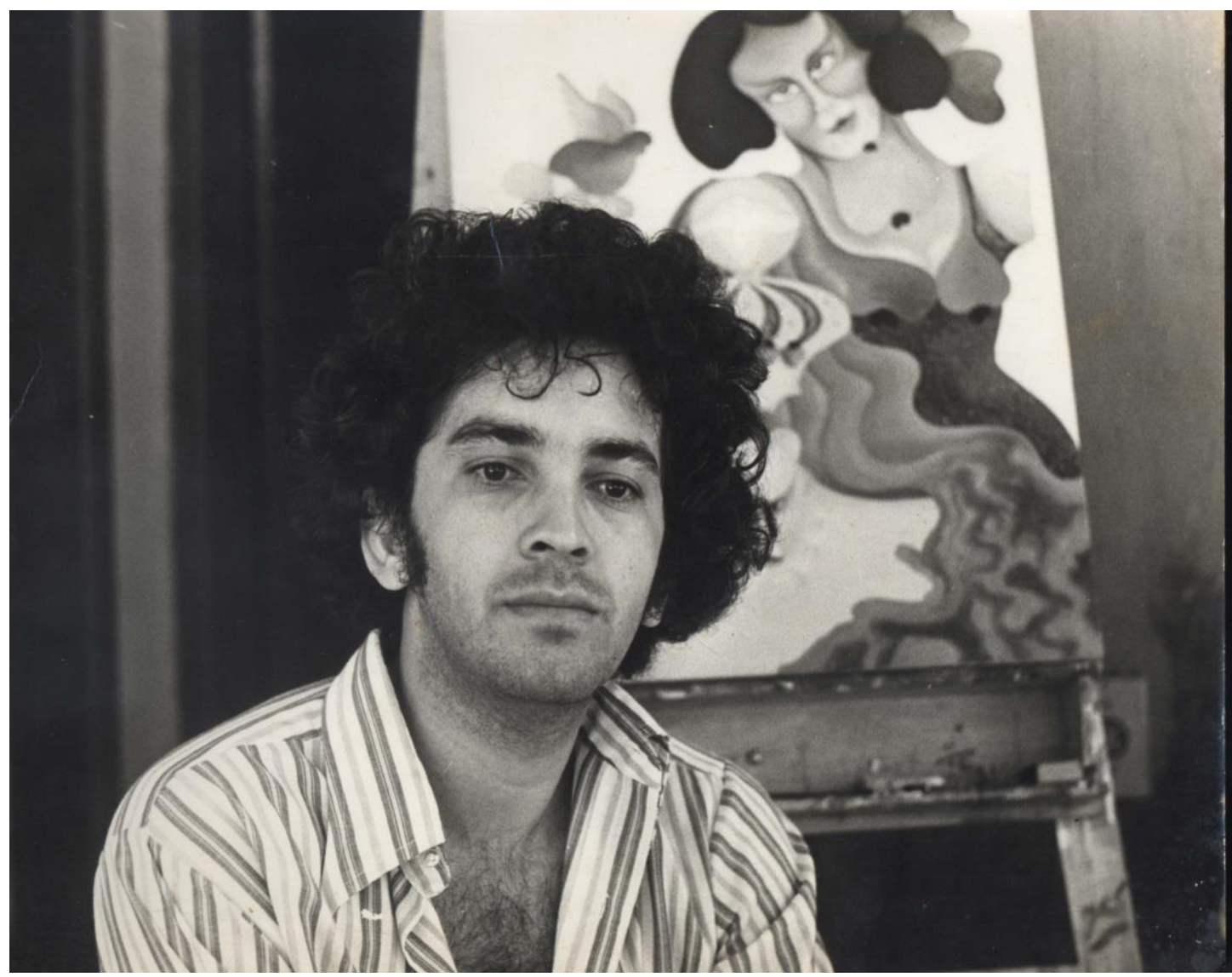

Fotografia 1 - João Sebastião, Ateliê Humberto Espíndola, Cuiabá-MT, 1986, foto de Aline Figueiredo Fonte: Arquivo do Artista.

Naquela época, o governo federal voltou os olhos para a região central do país, se deslocou do litoral, para Brasília, enquanto isso, em Campo Grande acontecia um intenso movimento de artes visais, liderado por Aline. Desse encontro, resultou uma amizade e muitos anos de trabalho, em todas as férias escolares, João Sebastião passava, no mínimo 30 dias, na casa da família do Espíndola, participando, ativamente, das ações artísticas em 
Campo Grande. Enquanto João morava na casa dos seus familiares, em Niterói, conciliava as atividades das artes com as escolares, visitando diversas exposições, conheceu muitos artistas plásticos, frequentou seus ateliês, teve uma vida muito rica em todos os aspectos.

A experiência de vida na escola no Rio de Janeiro, cujos colegas questionavam o tempo todo, sobre a existência de onças e outros animais perigosos, circulando no meio da cidade de Cuiabá, provocou no jovem João Sebastião, uma inquietação, que aflorou ao retornar para a região de origem, quando ele procurava um elemento que representasse sua região, foi assim, que nasceu a ONÇA, mas não era apenas o animal, ela precisava ter algo mais que isso, então ele elaborou aquilo, que o marcou, que o consagrou: a figura antropomórfica, mítica, encantada, provocativa, curiosa, que observa na espreita. Um ser descrito por Aline Figueiredo (2010:117) ““'homem-bicho-santo””, os cenários criados por João Sebastião transcendem os limites do real, os seres encantados, a celebração da natureza, a ambiência composta pela fauna, flora, a religiosidade, a devoção, a magia, na imensidão da espacialidade do cerrado, fez de João Sebastião da Costa um artista singular.

Este texto apresenta um breve estudo sobre uma pintura de João Sebastião, intitulada São João Sebastião na Barriga do Minhocão, de 1977, em pleno período da ditadura civil militar. O artista desafia os conceitos, os preconceitos, os valores religiosos, éticos, morais, altamente patrulhados. Para entender essa pintura, é necessário relatar sobre o São Sebastião, e a lenda do Minhocão do Parí. Segundo Bertoloto (1992, p. 49) "'Trata-se de uma cobra de tamanho descomunal que, nas épocas de cheia, aparece no Rio Cuiabá. Sua estória afirma que a mesma tem sua cabeça presa ao altar da igreja de São Gonçalo, enquanto seu corpo e sua calda ficam soltos a flutuar pelo rio"”. Desta forma, se as pessoas religiosas não mantiverem suas rezas, ou seja, as novenas aos santos. ““‘... o Minhocão desprende-se do altar e passa a deslocar-se pelo rio, provocando grandes enchentes. Nessas ocasiões, ele aparece colocando em risco a vida das pessoas, assustando os pescadores, virando embarcações na zona montante do rio"”. (BERTOLOTO, 1992, p. 49).

São Sebastião é um mártir da igreja católica, o defensor da igreja, teve seu corpo imolado por duas vezes, pois ele foi chefe da guarda do Imperador Romano Diocleciano. Denunciado por ser cristão, uma vez que, ele nascera em lar cristão na cidade de Narbona, França. Do ano 300 a 303 (d.C.) houve muita perseguição, aos cristãos, um período da decadência do império romano, durante esses três anos ouve muitas mortes. Enquanto o soldado Sebastião chefiava a guarda do imperador, não abandonou as práticas religiosas, não deixou de visitar os cristãos prisioneiros, mantendo o fervor nos quais, tinham a morte cruel, como o fim das suas vidas. Até que um dia, o soldado foi denunciado ao imperador, que, 
surpreso com tal revelação, mandou chamar os exímios arqueiros da Numídia, uma região desértica da África, onde a prática da caça só era possível, usando arco e flechas. Diocleciano ordenou que o soldado fosse amarrado numa árvore seminu, e que ele fosse cravado de flechas, mas que elas não atingissem suas vísceras, para que sua morte fosse lenta e dolorida. Assim, os arqueiros executaram a ordem do imperador, e acreditando que o soldado estivesse morto, foram embora, e o deixaram amarrado na árvore. Vários amigos cristãos se prepararam para fazer o enterro do soldado, quando retiraram o corpo da árvore, constataram que Sebastião, ainda estava vivo, ele foi levado para casa, as feridas tratadas, o soldado decidiu enfrentar o imperador, mesmo contra a vontade dos seus amigos.

Era o dia 20 de janeiro, o imperador Diocleciano estava no templo do deus Hércules acompanhado de sacerdotes pagãos, entre tantos homens nobres, foi concedida uma audiência pública àqueles que desejassem apresentar alguma queixa. Sebastião se apresentou e reclamou das atitudes do imperador, diante de tanta perseguição e crueldade aos cristãos. Naquele momento, Diocleciano ficou surpreso na presença daquele soldado, que até em tão, havia sido dado como morto. Imediatamente, ordenou aos guardas, que o executasse na frente de todos e dele mesmo, para se ter a certeza da sua morte. Os soldados moeram o corpo de Sebastião de pauladas e lanças. O imperador ordenou, que o corpo fosse jogado no esgoto da cidade. Mais uma vez, Sebastião foi socorrido pelos cristãos, que resgataram seu corpo e o sepultaram na Via Ápia. Após, a morte de Sebastião os cristãos, que admiravam seu trabalho junto àqueles presos condenados à morte pela prática religiosa, começaram a rezar por ele, essa prática se intensificou durante a epidemia da peste, quando, no ano de 680 a Itália foi acometida por uma grande peste, que matou muita gente. Nesse período muitos cristãos rogaram cura, e foram atendidos, e prometiam construir uma igreja em homenagem ao Sebastião. Assim sendo, São Sebastião é o protetor contra as pestes, a fome, e a guerra, ele é o defensor da Igreja, por ter desafiado as leis romanas em nome dela.

Na pintura em estudo, o artista apresenta a figura do São Sebastião, repousando no interior da barriga da serpente, que nos remete à lenda do Minhocão do Parí, que habita o universo mítico dos ribeirinhos do Rio Cuiabá. O santo posicionado na parte inferior do quadro, devorado pela serpente numa atmosfera singular, sobrepõe aos ditames judaicocristãos, uma vez que, o artista cria um cenário mítico, jocoso, cercado de religiosidade, confirmando seu lugar de fala, que remete ao processo colonial na América Latina. Os fluxos de informações que transitaram na América Latina, numa circulação e encontro de objetos e pessoas, com suas práticas culturais distintas, que se cruzam e produzem outras práticas 
culturais singulares, como se vê na pintura de João Sebastião da Costa, a representação decolonial dos seus santos.

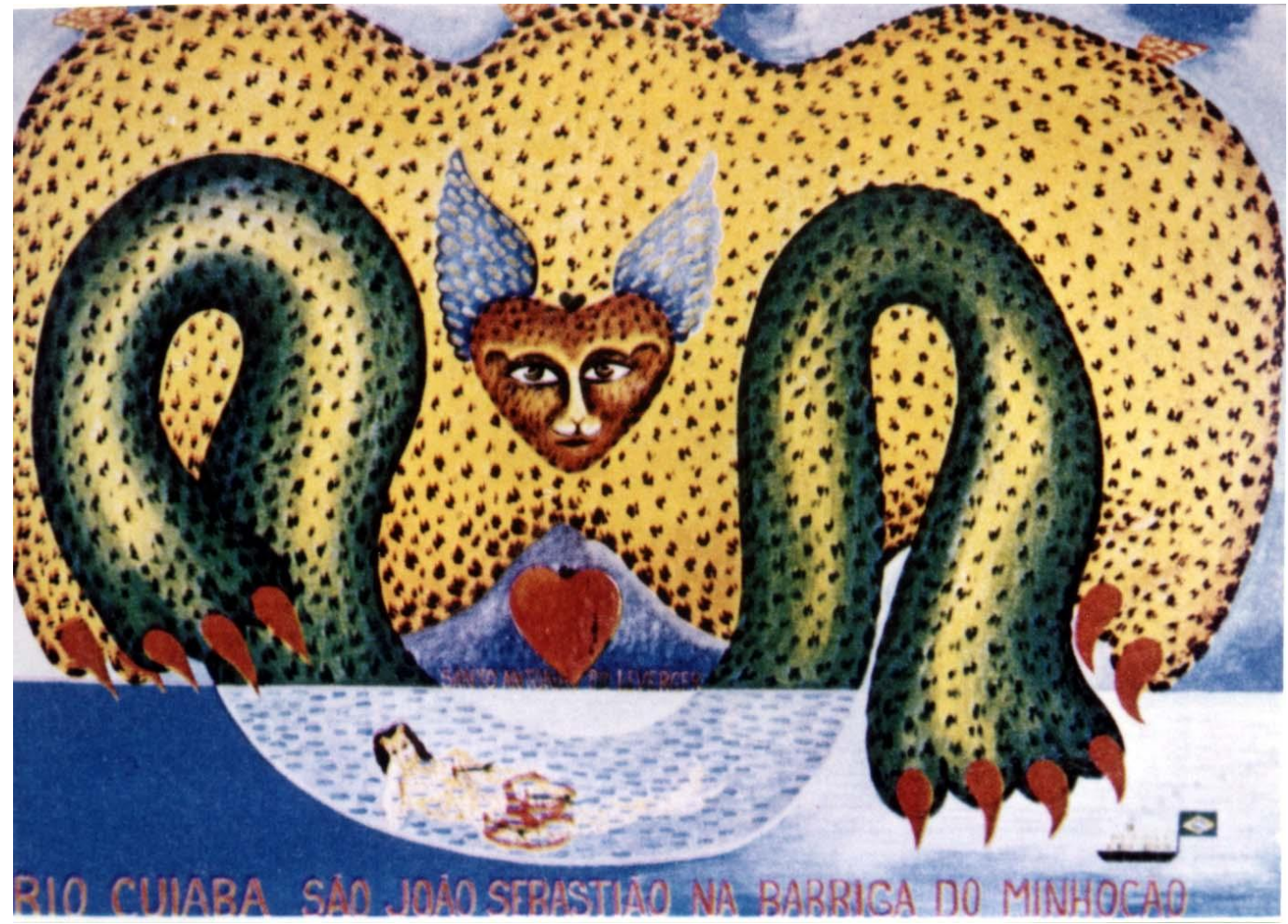

Fotografia 2 - São João Sebastião na Barriga do Minhocão, pintura, 87x110 cm, 1977, foto de Aline Figueiredo Fonte: Arquivo do Artista.

\section{Descrição e Análise da Iconografia}

A pintura de João Sebastião, intitulada São João Sebastião na Barriga do Minhocão, de 1977 em pleno período da ditadura civil militar. O artista desafia os conceitos, os preconceitos, os valores religiosos, éticos, morais, altamente patrulhados.

Ao fundo, ocupando toda a extensão da tela há uma enorme pata com unhas afiadas da onça pintada; no meio dela aparece um rosto efeminado em forma de caju com asas azuladas; logo abaixo vê-se o Morro de Santo Antônio de Leverger e no centro deste, uma representação de um coração vermelho em forma de caju, complementando a parte inferior da imagem, vê-se delgadamente a serpente que habita os rios - O Minhocão - em um verde mesclado de amarelo e com unhas afiadas, tal qual às da onça, confundindo-se minhocãoonça- minhocão. Dentro da barriga da serpente - que imersa na água - repousa São Sebastião, belo e formoso sem o menor constrangimento. 
A serpente que habita as águas do rio Cuiabá devora o mártir, sobrepondo-se à santidade purificada ao ser mais elevado espiritualmente. $\mathrm{O}$ santo repousa dentro da barriga da serpente, mergulhada na água. A água, seu ambiente, é cosmogônica, mágica e medicinal. Seu poder vem, principalmente, do fato de que nada lhe resiste: penetra em todos os lugares, devagar e profundamente, rasgando o seio da terra, mãe-irmã-mulher, e simboliza a eternidade do ciclo de construção e destruição. A água fertiliza a terra, sem ela não há vida. Porém, quando em desequilíbrio, leva tudo aquilo que está ao seu redor. Depois, devolve e faz tudo nascer novo, de novo. ““'Essa força de renovação que é evocada no batismo, quando a água representa o principal instrumento de regeneração espiritual"”' (MOREIRA, 2003, p. 95). Enquanto a onça/jaguar “"'gera inúmeras narrativas que carregam em si, uma gama de simbologia colocada pelo homem e sua civilização, incluindo povos de diferentes nações, como os índios de Mato Grosso e o Brasil como um todo"”. (MOREIRA, 2003, p. 70).

Entre os índios da América Central, quatro jaguares velam sobre as quatro vias de acesso ao centro da aldeia. $\mathrm{O}$ costume provém da antiga crença maia segundo a qual quatro jaguares míticos seriam, desde as origens, os guardiães dos campos de milho. Na terceira idade Maia-Quiché, que corresponde à agricultura, e, portanto, à preminência dos cultos lunares, o jaguar representa a deusa lua-terra. ... para os maias, o jaguar é, sobretudo, uma divindade ctoniana, expressão suprema das forças internas da terra. Ele é o deus do número Nove, expressão das regiões de baixo. Senhor do mundo subterrâneo ... deus do interior da terra, ele leva nas costas uma concha marinha, símbolo da grande-mãe Lua, e, por extensão, símbolo do nascimento. Divindade ctoniana, o jaguar é, igualmente, senhor das montanhas, do eco, dos animais selvagens e dos tambores de chamada. Dão-lhe o nome de coração da montanha.

Para os tupinambás, o jaguar é uma divindade uraniana, celeste, semelhante a um cão e azul como o lápis-lazúli. Sua morada fica no alto dos céus. Ele tem duas cabeças, para devorar o Sol e a Lua (explicação dos eclipses). No fim do mundo ele descerá à terra e se lançará sobre os homens para fazer deles sua presa.

Num mito dos índios iurucarés do Brasil ... o último dos jaguares, depois de ver dizimada sua família por um herói humano que vinga os seus, sobe numa árvore e pede socorro ao Sol e à Lua. O Sol não lhe dá ouvidos mas a Lua o recolhe e esconde. Ele vive desde então com ela e é desde esse tempo que os jaguares são noturnos.

A mesma crença se encontra entre as numerosas tribos indígenas da América do Sul, Peru, na Bolívia, no Equador, nas Guianas, principalmente chanés, uitotos (Colômbia), bacairis do Xingu (Brasil), tupis-guaranis (Brasil), caraíbas, makusis, warais da Guiana venezuelana...

Em numerosos mitos dos índios da América do Sul, intervém um jaguar de quatro olhos, o que simboliza o Dom de clarividência dos espíritos noturnos e ctonianos. Nos mitos brasileiros referentes à origem do fogo ... ele aparece como o herói civilizador que dá o fogo aos homens ao mesmo tempo que as primeiras indústrias, sobretudo a tecelagem do algodão. $\mathrm{E}$, todavia, ele aparece também não como o inventor do fogo mas como o seu guardião, depositário e primeiro usuário. Ele não explica a técnica de acender fogo, o que confirma sua função ctoniana. $O$ jaguar não é um demiurgo mas, talvez, um antepassado." (CHEVALIER, 1996, p. 510-511) 


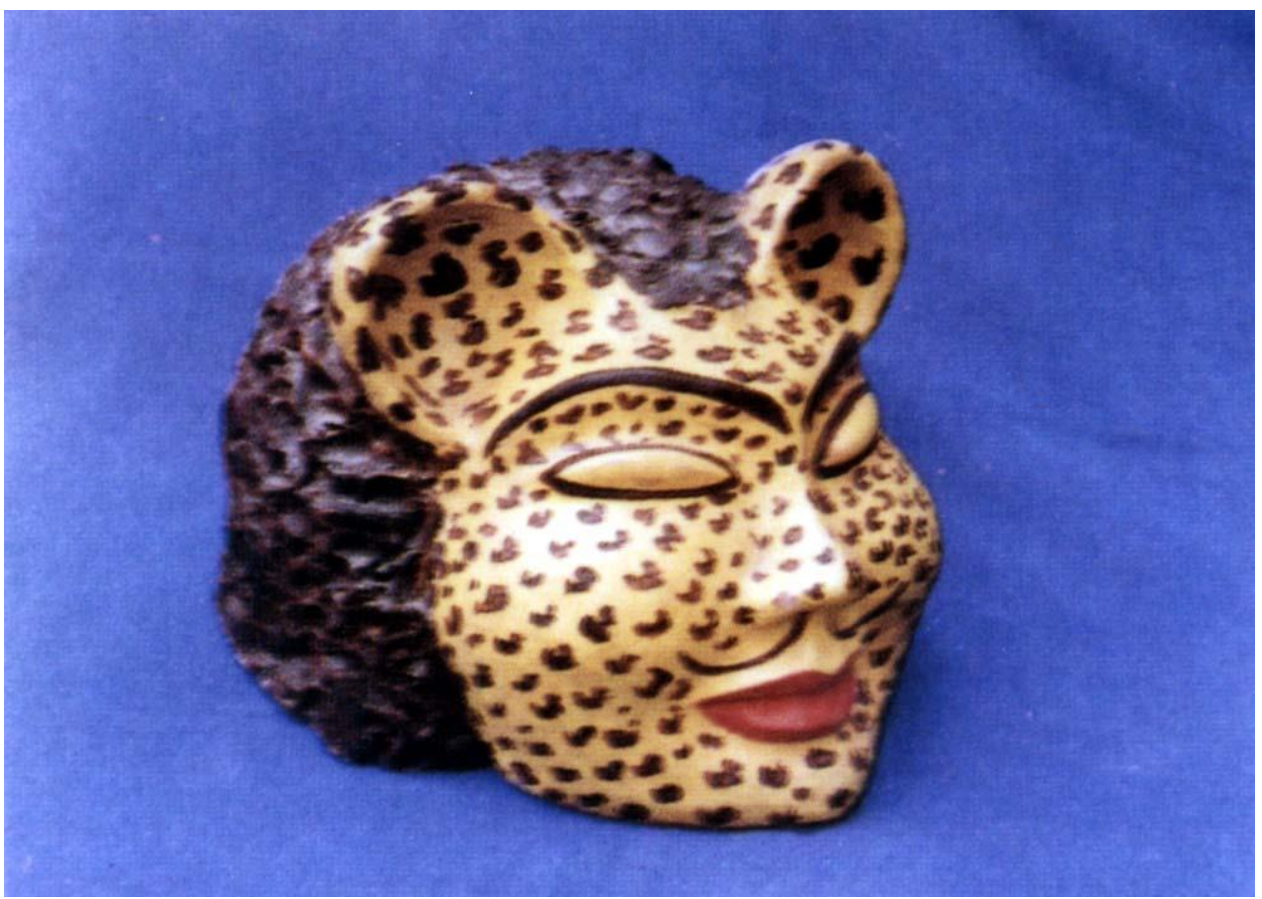

Fotografia 3 - João Sebastião da Costa, cerâmica, 17 cm, vertical, 1985, Foto: José Maurício de Melo Fonte: Arquivo de Aline Figueiredo

Ao compor a pintura São João Sebastião na Barriga do Minhocão, João apresenta uma justaposição de imagens, bastante utilizada no período arcaico do grotesco.

Nos períodos iniciais arcaicos do grotesco, o tempo aparece como uma simples justaposição (praticamente simultânea das duas fases do desenvolvimento: começo e fim: inverno-primavera, morte-nascimento. Essas imagens ainda primitivas movemse no círculo biocósmico do ciclo vital produtor da natureza e o homem. A sucessão das estações, a semeadura, a concepção, a morte e o crescimento são os componentes dessa vida produtora. A noção implícita do tempo contida nessas antiquíssimas imagens é a noção do tempo cíclico da vida natural e biológica. Mas, evidentemente, as imagens grotescas não permanecem nesse estágio primitivo. $\mathrm{O}$ sentimento do tempo e da sucessão das estações que lhes é próprio, amplia-se, aprofunda-se e abarca os fenômenos sociais e históricas; seu caráter cíclico é superado e eleva-se à concepção histórica do tempo. E então as imagens grotescas, com sua atitude fundamental diante da sucessão das estações, com sua ambivalência, convertem-se no principal meio de expressão artística. (BAKHTIN, 1987, p. 22)

Se para BAHKTIN a justaposição nos tempos arcaicos aparece como fases de desenvolvimento, compreendendo começo e fim, morte e nascimento, podemos inferir que João Sebastião provoca o espectador, diante de um santo devorado por uma serpente, repousando em sua barriga mergulhada na água, matando o santo (a serpente o engole), mata o santo de novo, ao colocá-lo dentro da barriga (mergulhada na água) que também é um símbolo de morte e vida em muitos mitos da criação do mundo. Depois de tudo isso, o santo renasce em nossa história de vida, lembrando que na cultura cristã o santo é colocado sempre num lugar acima da cabeça do devoto. O santo se destaca no altar. Os opostos se entrelaçam 
na produção de João Sebastião, rompendo com o tradicional e com todas as regras. Podemos inferir que o minhocão sebastiano é um elemento de dispersão, pelo fato de estar no imaginário popular, que por sua vez, também pode estar na tela do artista, tomando o elemento do contexto original e dando a ele uma outra conotação, colocando-o em outro lugar. Assim, o Minhocão que habita o rio está na tela de João tendo na sua barriga um santo, isto provoca uma mudança radical - rompem-se as regras - causando a carnavalização, ou seja, ao integrar os elementos jocosos com os elementos da cultura dominante, a irreverência ridiculariza aquilo que é oficial.

Na pintura de João Sebastião, também, aparecem os elementos do Brasil Colônia: os dogmas da igreja (o santo); a punição da serpente (se o cristão não cumprir suas obrigações religiosas); as línguas imperiais (castellano, português, italiano), mas também, um lugar: o lugar da memória colonial, onde são armazenadas as feridas da colônia, ““‘a los lugares de la memoria colonial: a las huellas de la herida colonial desde donde se teje el pensamento decolonial"”.' (MIGNOLO 2008, p. 252). Essas feridas que funcionam como um bumerangue, que vão e voltam com uma força descomunal, neste caso, os elementos da cultura cuiabana em comunhão com elementos da cultura universal, ou seja: Cuiabá e a devoção pelo São Sebastião, essa memória colonial, repousando em nossos bens de cultura, retorna com vigor, reafirmando o giro decolonial, no santo deitado, languidamente, no interior da barriga da serpente. O santo não aparece na parte superior da tela, em destaque, conforme as práticas religiosas, onde os santos são venerados, e colocados em altares, acima dos devotos, para confirmar a supremacia do colonizador, que apresentou aos habitantes da nova colônia um outro modo de viver, reviver na fé da sua religião.

Assim como também, a destruição do corpo do mártir da igreja católica, faz um contraponto com as práticas dos povos originais, os verdadeiros donos das terras da América Latina, quando a pintura corporal é realizada em diversas situações, confirmando uma identidade étnica, mesmo nos dias atuais, constituindo narrativas míticas, os saberes gráficos dos povos primevos, remetem à uma memória antiga e cíclica.

a pintura corporal é um elemento da constituição da alteridade cultural. Porque, tanto no passado, quanto na atualidade, continua sendo importante para os povos indígenas. Não é exagero afirmar que se deve a ela o "retorno da 'memória cíclica' das etnias, responsável pela atualização das mitologias dos grafismos, (Taukane et ali, 2018, p. 02)

O Minhocão do Parí tem sua cabeça presa no altar da Igreja de São Gonçalo, enquanto o restante do corpo flutua no Rio Cuiabá. Novamente, aparece o encantamento dos seres da 
pintura de João Sebastião, enquanto o Minhocão da Baía de Chacororé, também encantado, assusta os moradores do Pantanal, constituindo um encantamento pela cultura e pela natureza.

Como o artista foi criado às margens do Rio Coxipó, numa região afastada do centro da cidade de Cuiabá, o menino desfrutou de todos os encantos que o cerrado ofereceu, banhado pelo rio caudaloso, em direção ao Cuiabá, que por sua vez, desagua no Pantanal. Comungou com os elementos vitais cuja água era mágica para ele, nos longos banhos de rio, as crianças envoltas aos animais de estimação, os vizinhos, as benzedeiras, as festas de santos, os ritos de passagens, os mitos, o folclore.

$\mathrm{Na}$ pintura em estudo, a água é mítica, comunga com seres encantados numa ambiência local-regional, onde a serpente que habita os rios, reina no Pantanal, devora o São Sebastião, provocando a antropofagia, na presença do caju com asas e fisionomia de gente (antropomórfica), une a todos com sua presença magnífica, criando um mundo mágico, da fantasia. Nas palavras do artista, “o caju é a fruta da amizade”. Segundo Leite (2003, p. 121) ““'Os aspectos antropomórficos imputados aos elementos naturais engendram paisagens muito diversas, mas, ao mesmo tempo, provocam o distanciamento delas com o que seria considerado natural ou humano"'. Nas águas encantadas cria-se seres híbridos na imaginação da população. ““Na paisagem encantada esta humanização rompe com o natural e, de certa forma, remete os elementos naturais para um outro universo, uma outra esfera, que é a do sobrenatural, sem perder, no entanto, seu lugar"”. (LEITE, 2003, p. 121).

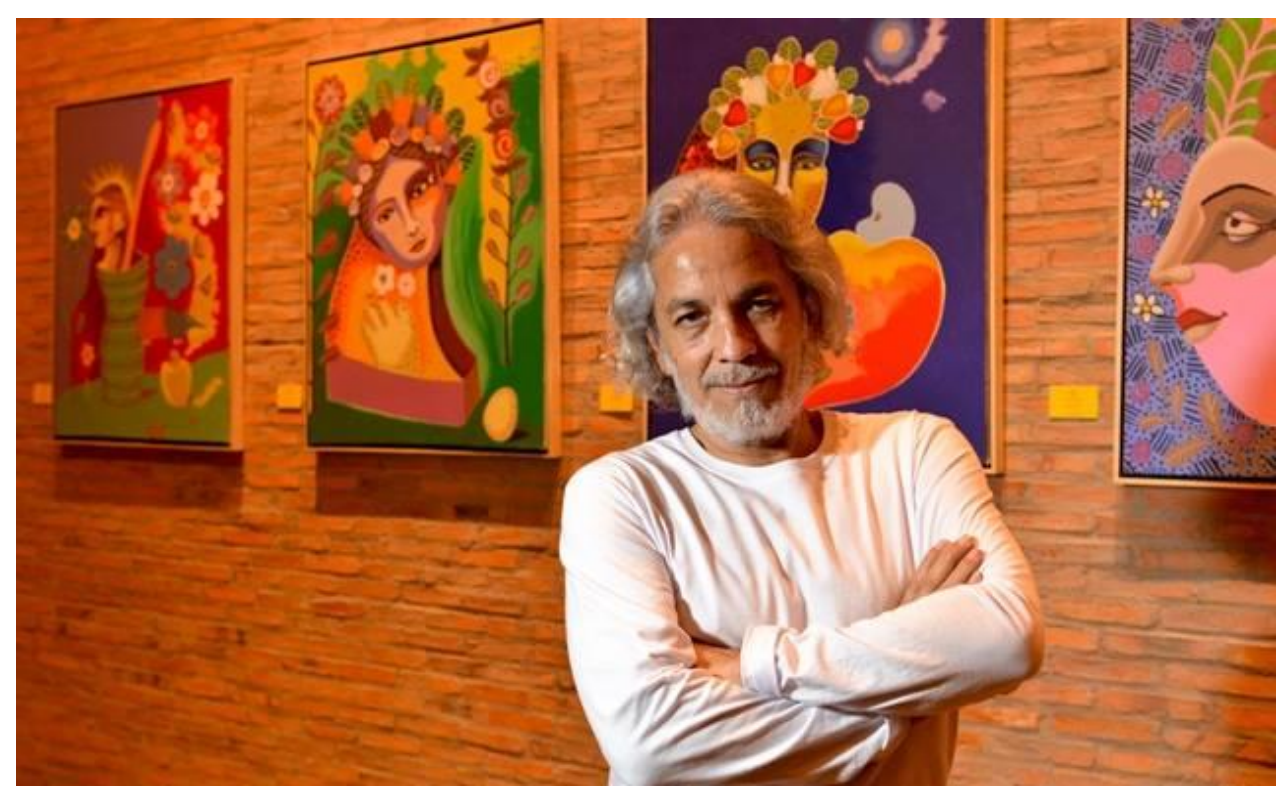

Fotografia 4 - João Sebastião da Costa

Fonte: Revista Camalote, Cuiabá-MT, acesso em: 20.11.2019 


\section{Conclusão}

A natureza rica, inspira o artista no seu processo de criação, reafirmando sua origem, seu passado, sua ancestralidade, que registram os mais de quinhentos anos de domínio dos países europeus, que massacraram os povos originais na América Latina. No caso brasileiro, a formação do povo que se deu com o cruzamento das raças dos colonizadores com os índios e negros, em que, cada um, trazendo consigo sua cultura, construiu um país múltiplo étnico, que infelizmente, o que prevaleceu foi a cultura dominante do colonizador.

Assim sendo, essa memória ancestral aparece nos registros da pintura de João Sebastião, ao compor imagens sagradas judaico-cristãs com elementos do seu lugar de origem, dialogando num espaço atemporal, único, singular, carregado de significados que afirmam seu compromisso de vida, ao firmar o pacto com o animal. A iconografia da onça se tornou um símbolo na presença da ferocidade das matas, que o artista personificou. Seu processo de criação consistia em elaborar vários croquis das figuras, idealizadas, depois reproduzidas, nas telas.

Suas obras de arte foram criadas a partir dos seus conhecimentos eruditos justapondo aos populares, a mítica de Mato Grosso configura aos do Brasil e da América Latina. O movimento decolonial desses grupos confirmam a força da ancestralidade, que movem uma energia contra qualquer tipo de governo, no formato de um boomerang. A força do povo que se move contra o monopólio das oligarquias, promovendo ações de cidadania singular, respeitando os laços ancestrais. A liberdade de criação em todas as esferas, promove uma reviravolta, contra as regras do jogo, por aqueles que se desprendem dos conhecimentos seguidos por um grupo de gente, que aceita jogar esse jogo. Isto implica na desobediência das normas impostas por grupos controladores do dinheiro no mundo, concentrado em poucas famílias milionárias.

João Sebastião da Costa não se rendeu aos ditames impostos, criou sua obra livre, construiu seu legado, que o consagrou no mundo das artes, no cenário brasileiro. Artista comprometido com as causas sociais e políticas, no ano de 2006 ele iniciou um estudo sobre o vermelho para chegar na cor do fogo, para construir uma série de objetos em protesto contra as queimadas. Ele pintou diversas paisagens cuiabanas, envoltas no vermelho, que representava o fogo das queimadas, nos tubos de PVC de diversos tamanhos. Preocupado com o acúmulo do lixo e com a poluição, elaborou pinturas em vários suportes, como as sacolas plásticas, o acetato, as PET foram arduamente usadas em formato de borboletas, máscaras de 
carnaval. O carnaval, que ele tanto amava. João Sebastião foi um artista engajado, atuante e destemido.

\section{Referências Bibliográficas}

BERTOLOTO, José Serafim. Gosto pelo natural ou luta ecológico? Um estudo sobre os aspectos contemporâneos das artes plásticas em Mato Grosso. São Paulo. 1992. 160 f. Dissertação (Mestrado em Artes) - Escola de Comunicação e Artes, Universidade de São Paulo.

BIEDERMANN, Hans. Dicionário Ilustrado de Símbolos, Trad. Glória Paschoal de Camargo, São Paulo - SP, Melhoramentos, 1993.

CIPOLINI, Pedro Carlos. Sebastião: um cristão para hoje. São Paulo, Edições Paulinas, 1981.

CHEVAliER. J.; GHEERBRANT. A. Dicionário de Símbolos. Trad. Vera da Costa e Silva. Rio de Janeiro, José Olympio, 1996.

FIGUEIREDO, Aline. ESPÍNDOLA, Humberto. Animação Cultural e Inventário do Acervo do Museu de Arte e de Cultura Popular, Cuiabá - MT, Entrelinhas, 2010.

LEITE, Mário Cezar Silva. Águas Encantadas de Chacororé: natureza, cultura, paisagens e mitos do Pantanal. Cuiabá - MT, Cathedral Unicen Publicações, 2003, (Coleção Tibanaré de Estudos Mato-Grossenses, v. 4).

MIGNOLO, Walter. A Opção De-Colonial: desprendimento e abertura. Um manifesto e um caso. Tabula Rasa, Colombia, nº 8, p. 243-281, 2008.

MOREIRA, Valéria Pereira. Comunicação das Imagens Religiosas e Representações de São Sebastião na Obra de João Sebastião na Obra de João Sebastião Francisco da Costa. 2003. 187 f. Dissertação (Mestrado em Comunicação e Semiótica), Pontifícia Universidade Católica de São Paulo. 2003.

TAUKANE, Isabel Teresa Cristina; BRANDÃO, Ludmila de Lima; SIQUEIRA, Aline Wendpap Nunes de. Etnosaberes e Pintura Corporal no Ciberespaço. In: CONGRESSO INTERNACIONAL INTERDISCIPLINAR SOCIAIS E HUMANIDADES, 7, 2018, Rio de Janeiro - RJ, Anais, 2018.

Figura - 3 http://www.revistacamalote.com.br/noticias/arte/2017/exposicao-prestahomenagem-ao-artista-plastico-joao-sebastiao-862 João Sebastião da Costa, Revista Camalote, Cuiabá-MT, acesso em: 20.11.2019 